\title{
EKSPLORASI LEGENDA "PARNAMORAAN" SUKU BATAK TOBA SEBAGAI BAHAN AJAR SASTRA PRODI PENDIDIKAN BAHASA DAN SASTRA INDONESIA UNIVERSITAS PRIMA INDONESIA
}

\author{
Amelia Simanungkalit ${ }^{1}$, Kartina Rahmadani Rambe ${ }^{2}$ \\ E-mail: ameliasimanungkalit@unprimdn.ac.id ${ }^{1}$, kartinarambe@gmail.com ${ }^{2}$ \\ ${ }^{1)}$ Dosen Universitas Prima Indonesia, ${ }^{2)}$ Dosen Sekolah Tinggi Ilmu Keguruan dan \\ Pendidikan YP Antasari
}

\begin{abstract}
ABSTRAK
Tujuan penelitian ini sebagai berikut (1) untuk mengetahui bentuk legenda Parnamoraan suku Batak Toba, (2) untuk melakukan eksplorasi legenda Parnamoraan suku Batak Toba sebagai bahan ajar sastra di Prodi Pendidikan Bahasa dan Sastra Indonesia Universitas Prima Indonesia. Metode penilitian ini adalah penelitian deskriptif. Sumber data penelitian ini adalah catatan hasil wawancara dengan informan suku Batak. Berdasarkan hasil analisis diperoleh hasil yaitu (1) bentuk legenda Parnomaraan suku Batak Toba yang di uraikan masyarakat setempat (2) eksplorasi legenda Parnamoraan suku Batak Toba sebagai bahan ajar sastra Prodi Pendidikan Bahasa dan Sastra Indonesia Universitas Prima Indonesia. Jurnal ini dilakukan sebagai luaran PDP tahun 2019 yang didanai oleh DRPM Ristekdikti.
\end{abstract}

Kata Kunci : Bentuk Legenda Parnamoraan ,Upaya Mengeksplorasi Legenda Parnamoraan.

\section{Pendahuluan}

Penyebaran sastra lisan dari mulut ke mulut menyebabkan banyak sastra lisan yang memudar karena tidak dapat dipertahankan. Selain keterbatasan memori manusia dalam mengingat, perkembangan teknologi yang semakin canggih di era globalisasi dewasa ini kut menggeser sastra lisan yang pernah ada, termasuk sastra lisan masyarakat batak Toba yang memiliki nilai budaya tinggi, yang seharusnya dapat dijaga kelestariannya. Padahal, Sastra lisan yang telah lama ada, lahir dan muncul dari masyarakat yang menjadikannya sebagai suatu tradisi dalam kelompok bermasyarakat. Sastra lisa hadir sebagai karya sastra yang beredar di masyarakat atau diwariskan secara turun temurun 
dalam bentuk lisan. Tentunya seluruh daerah memiliki sastra lisan yang umumnya akan berbeda dengan yang lain. Sastra lisan, baik bentuk puisi maupun cerita tidak terlepas dari nilainilai yang terkandung di dalamnya, nilai pendidikan, moral, etika, dan masih banyak lagi nilai- nilai kehidupan yang positif yang amat penting ditanamkan ke dalam kehidupan. Nilai-nilai tersebut mencerminkan pola hidup masyarakat tempat sastra lisan itu pernah hidup dan berkembang.

Berkaitan dengan hal tersebut, perlu dieksplorasi sastra lisan, khususnya sastra lisan di Sumatera Utara. Ekplorasi legenda pada umumnya merupakan kegiatan penjelajahan terhadap legenda yang sebelumnya masyarakat belum mengetahui keberadaan legenda tersebut. Eksplorasi yang dapay dilakukan peneliti, pada legenda "parnamoraan" bertujuan untuk mengeksplor cerita legenda "parnamoraan" baik dalam segi asal mula legenda maupun nilai yang terkandung dalam legenda tersebut. Perkembangan teknologi saat ini membuat kurangnya minat baca sesorang untuk mengetahui legenda.

$\begin{array}{lcr}\text { Maka } & \text { dari itu penulis } \\ \text { melakukan } & \text { penelitian } & \text { tentang } \\ \text { "Eksplorasi } & \text { Legenda } & \text { Parnaomoraan }\end{array}$

sebagai bahan ajar sastra Program Studi Pendidikan Bahasa dan Sastra Indonesia Universitas Prima Indonesia". Peneliti merasa tertarik untuk mengkaji kemudian mengdokumentasikannya, harapan yang ingin dicapai dalam penelitian ini dapat menjadikan legenda tersebut sebagai bahan ajarsastra. Untuk itu, tujuan penelitian ini secara spesifik sebagai berikut. (1) Untuk mengetahui dan mempublikasikan bentuk legenda "Parnamoraan" dengan jelas yang diuraikan oleh masyarakat suku bataktoba. (2) Untuk mengeksplorasi legenda "Parnamoraan" sebagai bahan ajar Sastra Prodi Pendidikan Bahasa dan Sastra Indonesia, Universitas Prima Indonesia.

$$
\text { Berkaitan dengan uraian }
$$
sebelumnya, Vansina (2011:10) sastra lisan (oral literature) adalah bagaian dari tradisi lisan (oral tradition) atau yang biasanya dikembangkan dalam kebudayaan lisan (oral culture) berupa pesa-pesan, cerita-cerita, atau kesaksiankesaksian, ataupun yang diwariskan secara lisan dari satu generasi ke generasi lainnya.

Saragih, dkk (2019:93) menyatakan bahwa eksplorasi Parnamoraan yang dilakukan terdapat pada suku batak toba tepatnya di Silalahi Sabungan. Legenda Parnamoraan menceritakan tentang seorang wanita 
(Deang Namora) yang sangat menyanyangi saudara laki-lakinya (Siraja Tambun) yang dia asuh sejak dari kecil yang berpisah setelah Siraja Tambun tumbuh dewasa pergi meninggalkan kampung Silahi untuk memperdalam ilmunya ke Nauli Basa. Karena merasa sedih ditinggal pergi oleh Siraja Tambun dan tidak diinginkan ikut bersamanya membuat Deang namora menjadi putus asa, ia setiap hari termenung merindukan kepulangan Siraja Tambun adiknya. Akhirnya dia memutuskan untuk tinggal disebuah pondok mengurung diri sambil bertenun membuat sepuluh ulos batak untuk ayah dan saudara laki-lakinya hingga pada akhirnya dia meninggal, tempat pertenunan tersebutlah kini dikenal dengan Parnamoraan.

\section{METODE}

$\begin{array}{ccr}\text { Metode } & \text { penelitian dalam } \\ \text { penelitian adalah metode penelitian }\end{array}$ deskriptif kualitatif. Metode itu digunakan agar peneltian dapat dideskripsikan secara sitematis, faktual, dan akurat. Penelitian ini akan dilaksanakan mulai bulan Oktober 2019 sampai Agustus 2020. Teknik pengumpulan data yang digunakan adalah teknik simak, bebas, cakap. Data penelitian ini adalah lisan berupa lengenda "Parnamoraan". Sumber data peneltian ini adalah informan dari masyarakat di desa Silalahi Sabungan, kec. Silalahi, kabupaten
Dairi. Teknik analisis data menggunakan analisis interaktif, berupa reduksi data, penyajian data, dan penarikan kesimpulan. Teknik validasi data menggunakan triangulasi data, teori dan sumber. Prosedur penelitian dalam penelitian ini adalah perencanaan, pelaksanaan dan penyusunan laporan.

\section{HASIL DAN PEMBAHASAN}

\section{Bentuk Legenda "Parnamoraan" menurut Masyarakat Suku Batak Toba}

Bentuk legenda Parnamoraan berasal dari suku Batak Toba. Bukti fisik legenda ini berupa tempat peninggalan bernama Parnamoraan yang berlokasi di Desa Silalahi Kec. Silalahi Sabungan Kab. Dairi Prov. Sumatera Utara. Legenda Parnamoraan menceritakan tentang seorang wanita yang bernama Deang Namora, seorang putri dari Raja Silalahi Sabungan. Deang Namora memiliki delapan saudara laki-laki, Deang Namora berpisah dengan saudara-saudaranya. Deang Namora menghabiskan harinya di suatu tempat yang disebut Parnamoraan yang merupakan tempat ia bertenun dan bersusah hati. Deang Namora memiliki kekuatan ajaib. Deang Namora mampu membuat kurang lebih 5 buah ulos dengan 1 gulung benang. Deang Namora seorang perempuan yang memiliki paras cantik dan 
hati yang baik. Deang Namora mengajari masyarakat bertenun.

Parnamoraan tempat tinggal Deang Namora dibangun dengan Sembilan tiang dan tidak memiliki tembok. Di dalam Parnamoraan tersebut terdapat batu besar, dimana batu tersebut dipakai Deang Namora untuk duduk sambil bertenun. Deang Namora meninggal dunia di tempat tersebut. Deang Namora dikuburkan di dalam gua yang tidak jauh dari tempat tinggalnya. Peninggalan Deang Namora yaitu Parnamoraan.

Tempat Parnamoraan itu menjadi tempat meminta permohonan kepada Deang Namora dengan dipandu oleh petuah di tempat itu melalui ritual-ritual. Tempat Parnamoraan itu juga menjadi tempat pernikahan beberapa pasangan suku Batak Toba yang mendiami wilayah tersebut. Tempat Parnamoraan tersebut dianggap memiliki nilai mistis. Pengunjung harus dipandu oleh petuah dan harus melakukan beberapa proses ritual.

Berdasarkan hasil penelitian tersebut, diketahui bahwa cerita tersebut dinyatakan sebagai legenda karena memiliki bentuk peninggalan, berupa batu. Legenda tersebut juga mengajarkan bahwa kita tidak boleh sembarangan ke tempattempat baru tanpa permisi. Hal tersebut sejalan dengan pernyataan Saragih, dkk (2019:96) bahwa Masyarakat yang datang ke tempat Parnamoraan harus berniat baik, karena jika masyarakat yang berniat buruk akan mendapatkan malapetaka sepulang dari tempat Parnamoraan tersebut. Sampai saat ini tempat Parnamoraan tersebut masih sakral.

\section{Eksplorasi Legenda "Parnamoraan" sebagai Bahan Ajar Sastra Prodi Pendidikan Bahasa dan Sastra Indonesia Universitas Prima Indonesia}

Hasil penelitian ini dapat digunakan menjadi bahan ajar di Prodi Pendidikan Bahasa dan Sastra Indonesia Universitas Prima Indonesia berupa legenda. Legenda adalah materi yang diajarkan di pembelajaran Sastra. Lebih tepatnya pada matakuliah Sastra Nusantara, Kajian Prosa, Apresia Sastra, dan Kritik Sastra. Selain digunakan sebagai bahan ajar, legenda Parnamoraan akan dipublikasikan dalam bentuk jurnal. Hal ini bertujuan untuk memperkenalkan cerita secara luas kepada masayarakat umum.

\section{SIMPULAN DAN SARAN}

\section{Simpulan}

Kesimpulan penelitian ini sebagai berikut.:

1. Legenda Parnamoraan berasal dari suku Batak Toba yang berasal dari desa Silalahi, Kecamatan Silalahi Sabungan, Kabupaten Dairi Sumatera Utara. Legenda 
Parnamoraan ini mengandung nilai suri teladan menghormati orang lain yang dapat dijadikan panutan oleh pembaca.

2. Upaya yang dilakukan peneliti untuk mengeksplorasi legenda Parnamoraan adalah dengan menjadikan legenda Parnamoraan sebagai bahan ajar Sastra di Prodi Pendidikan Bahasa dan Sastra Indonesia Universitas Prima Indonesia pada matakuliah Sastra Nusantara, Kajian Prosa, Apresia Sastra, dan Kritik Sastra.

\section{Saran}

Peneliti memberikan saran antara lain .

1. Dosen dan Program studi

Penelitian ini dapat dijadikan sebagai bahan ajar matakuliah Sastra Nusantara, Kajian Prosa, Apresia Sastra, dan Kritik Sastra

2. Peneliti selanjutnya

Dapat dilakukan penelitian selanjutnya mengenai nilai-nilai kehidupan yang terdapat di dalam legenda Parnamoraan,.

\section{Daftar Pustaka}

Bakkar dkk. 1981. Sastra Lisan. Jakarta :

UI Press.
KN Saragih, DN Nababan, SDB Ginting Bahasa Indonesia Prima (BIP), 2019.

Warren, Wellek. 2014. Teori Sastra.

Jakarta : PT. Buku Seru. Amir. 2013. Sastra Lisan. Yogyakarta : Jalasutra. 